\title{
Can an IL13 -1112 C/T (rs1800925) polymorphism predict responsiveness to neoadjuvant chemoradiotherapy and survival of Chinese Han patients with locally advanced rectal cancer?
}

\author{
Lin Xiao ${ }^{1,2,3, *}$, Xin Yu ${ }^{1,2, *}$, Rong Zhang ${ }^{2,4, *}$, Hui Chang ${ }^{1,2}$, Shaoyan $\mathbf{X i}^{2,5}$, Weiwei Xiao ${ }^{1,2}$, \\ Zhifan Zeng ${ }^{1,2}$, Huizhong Zhang ${ }^{2,5}$, Ruihua $X^{2,6}$, Yuanhong Gao ${ }^{1,2}$ \\ ${ }^{1}$ Department of Radiation Oncology, Sun Yat-sen University Cancer Center, Guangzhou, China \\ 2 State Key Laboratory of Oncology in South China, Collaborative Innovation Center of Cancer Medicine, Guangzhou, China \\ 3 Department of Oncology, Section II, Jiangmen Central Hospital, Affiliated Jiangmen Hospital of Sun Yat-sen University, \\ Jiangmen, China \\ ${ }^{4}$ Department of Endoscopy and Laser, Sun Yat-sen University Cancer Center, Guangzhou, China \\ ${ }^{5}$ Department of Pathology, Sun Yat-sen University Cancer Center, Guangzhou, China \\ ${ }^{6}$ Department of Medical Oncology, Sun Yat-sen University Cancer Center, Guangzhou, China \\ * These authors contributed equally to the paper \\ Correspondence to: Yuanhong Gao, email: gaoyh@sysucc.org.cn \\ Ruihua XU, email: xurh@sysucc.org.cn
}

Keywords: interleukin-13, single-nucleotide polymorphism, locally advanced rectal cancer, neoadjuvant chemoradiotherapy, prognosis

Received: December 04, $2015 \quad$ Accepted: April 16, 2016

Published: May 04, 2016

\section{ABSTRACT}

We sought to determine whether a polymorphism in the Interleukin 13 gene (IL13), $1112 \mathrm{C} / \mathrm{T}$ (rs1800925) predicts responsiveness to neoadjuvant chemoradiotherapy (neoCRT) and prognosis in Chinese Han patients with locally advanced rectal cancer (LARC). Pre-treatment biopsies of primary rectal lesion and surgical specimens were collected from 58 patients with LARC, who were treated with neoCRT and surgery. Tumor DNA was extracted from these biopsies and sequenced to analyze the rs 1800925 polymorphism. The tumor response to neoCRT was categorized using a tumor regression grade (TRG, 0-2 were poor responders; 3-4 were good responders). Analyses of progression free survival (PFS) and overall survival (OS) were carried out using the Kaplan-Meier method. Of the forty-six patients for whom tumor DNA was successfully sequenced, 23 were good responders to neoCRT (11 patients with a pathological complete response, i.e. PCR) and the other 23 were poor responders. Good and poor responders were equally likely to have a $\mathrm{C} / \mathrm{C}$ genotype at rs1800925 $(73.9 \%)$ as a T/T or C/T genotype (26.1\%). There were no differences between the $\mathrm{C} / \mathrm{C}$ and $\mathrm{T} / \mathrm{T}+\mathrm{C} / \mathrm{T}$ genotypes with respect to the ypT0-2 ratio (38.2\% vs. $41.7 \%, P=1.0)$, ypNO nodal status $(67.6 \%$ vs. $50.0 \%, P=0.314)$, 6 -year PFS (67.6\% vs. $50 \%, P=0.274$ ), or 6 -year OS (76.5\% vs. $66.7 \%, P=0.441)$. Thus, the IL13-1112 C/T (rs1800925) polymorphism does not predict responsiveness to neoCRT or prognosis of Chinese Han patients with LARC.

\section{INTRODUCTION}

Rectal cancer is one of the ten most common cancers and is a leading causes of cancer death in China
[1]. Neoadjuvant chemoradiotherapy (neoCRT) followed by total mesorectal excision (TME) is currently the standard treatment for locally advanced rectal cancer (LARC, i.e $\mathrm{T} 3 \sim \mathrm{T} 4 / \mathrm{N}+$ ), resulting in improved local 
control, R0 resection, and pathological tumor downstaging [2]. However, neoCRT is not equally beneficial for all patients, as $12 \%$ to $24 \%$ of patients have a minimal response to neoCRT, while $10 \%$ to $34.7 \%$ of patients have complete loss of residual cancer cells in surgical specimens, i.e. pathological complete response (pCR) [3$6]$. Patients with pCR have a better prognosis than those with non-pCR $[2,5]$. Thus, identification of predictive markers of cancer response to neoCRT is of clinical importance for personalized therapy. For those with a priori cancer resistant to chemoradiotherapy, more intensive preoperative treatment regimens may be better than conventional neoCRT [7]. In contrast, for patients achieving a clinical complete response (cCR) after neoCRT, radical surgery may be potentially spared or deferred with the help of strict observation [8-10].

How to accurately predict the responsiveness to neoCRT still remains a challenge [11]. A series of clinical parameters such as radiation dose, concomitant chemotherapy protocols $[11,12]$, pre-treatment serum carcinoembryonic antigen (CEA) level [13], interval between completion of neoCRT and surgery [14, 15], and complication of Diabetes Mellitus [16] has been used to predict tumor responsiveness to neoCRT. Many studies have been carried out to seek predictive biological biomarkers of tumor response to neoCRT, and have mostly focused on a series of proteins involved in apoptosis (Smac [17] and Bax [18]), cell cycle arrest (p21), and distant metastasis (MMP-9 [19]). However, none of these targets have been validated and incorporated into clinical practice. One promising approach to finding key molecular markers is to study single nucleotide polymorphisms (SNPs) or mutations of cancer related genes [7, 11, 20-21].

Cytokines are one of the most common components of tumor inflammatory microenvironment, especially for colorectal cancers [22]. IL13, one of many immune inhibitory cytokines generated by Th2 lymphocytes, is involved in tumor development by inhibiting immune surveillance functions of natural killer cells, CD4 (+) Th1 cells and CD8 $(+)$ cytotoxic T lymphocytes $[23,24]$. There are several SNPs in the IL13 gene, such as a functional polymorphism, rs1800925, located in the promoter, rs2066960 in intron 1, rs1295686 in intron 3, rs20541 in exon 4, and rs1295685 in exon 4 [25]. Recently, there has been more interest in rs1800925 (1112 C/T) since it was found that a $\mathrm{C} / \mathrm{T}$ genotype at this locus was associated with a higher risk of colon cancer occurrence in the Polish population [26]. C/T and T/T genotype were also associated with a higher risk of colorectal cancer and inflammatory bowel diseases, such as ulcerative colitis and Crohn's disease [27]. This SNP was also associated with tumor response to neoCRT in Caucasian patients with LARC, with patients harboring the $\mathrm{T}$ allele having a poorer response to neoCRT [7].

However, different ethnicities may have different allele frequencies for a SNP. It is not clear whether SNP rs1800925 in IL13 has an association with response to neoCRT in Han Chinese patients. In this study, we explored the association between SNP rs1800925 (IL13 $1112 \mathrm{C} / \mathrm{T}$ ) and response to neoCRT and prognosis for 58 Chinese Han patients with LARC treated with neoCRT and surgery.

\section{RESULTS}

\section{Pathological assessment of surgically resected specimen}

Among the 58 patients included in this study, 28 (48.3\%) were good responders: 12 were TRG3 and 16 were TRG4 ( 15 patients had pCR, and 1 had pCR at the rectum primary tumor but had $\mathrm{pN} 1 \mathrm{a}$ disease for postoperative lymph node staging). Thirty $(51.7 \%)$ patients were poor responders: 8 displaying dominant tumor mass (i.e. TRG1) and 22 with few tumor cells or groups (TRG2) at rectal primary lesion.

\section{Correlation between rs1800925 polymorphisms and responsiveness to neoCRT}

Of the 58 cases in this study, DNA from 8 formalin-fixed, paraffin-embedded specimens could not be successfully extracted, and a genotype could not be determined for 4 samples. The other 46 patients' DNA from paraffin-embedded specimens were successfully sequenced; 23 of them were good responders (11 patients with pCR) and the other 23 were poor responders. The genotypes of rs 1800925 polymorphism were as follows: 34 cases with $\mathrm{C} / \mathrm{C}$ genotype, 6 with T/T, and 6 with $\mathrm{C} / \mathrm{T}$. Table 2 shows the comparison between good responders and poor responders; no difference was observed between them. Table 3 shows the comparison of rs1800925 polymorphisms between patients with $\mathrm{pCR}$ and non-pCR; there was also no difference between these two groups $(P$ $>0.05)$.

\section{Association between rs1800925 genotypes and yp T/ypN staging}

Table 4 shows the correlation between rs 1800925 genotypes and different ypT/ypN staging in the 46 patients. There were no differences between groups $(P>$ $0.05)$. 
Table 1: Patient characteristics and their association with responsiveness to neoadjuvant chemoradiotherapy

\begin{tabular}{|c|c|c|c|c|}
\hline \multirow{2}{*}{ Parameter } & \multirow[b]{2}{*}{ Cases (n) } & \multicolumn{2}{|c|}{ Response to RT (n, \%) } & \multirow{2}{*}{$P$ value } \\
\hline & & Good & Bad & \\
\hline \multicolumn{5}{|l|}{ Gender } \\
\hline Male & 41 & $21(51.2)$ & $20(48.8)$ & \multirow{2}{*}{0.570} \\
\hline Female & 17 & $7(41.2)$ & $10(58.8)$ & \\
\hline \multicolumn{5}{|l|}{ Tumor grade } \\
\hline $\begin{array}{l}\text { Well-moderately } \\
\text { differentiated }\end{array}$ & 26 & $11(42.3)$ & $15(57.7)$ & \multirow[t]{2}{*}{0.753} \\
\hline Poor differentiated & 16 & $8(50.0)$ & $8(50.0)$ & \\
\hline Gx & 16 & $9(56.3)$ & $7(43.7)$ & \\
\hline \multicolumn{5}{|c|}{\begin{tabular}{|l|l|}
$\begin{array}{l}\text { Pretreatment UICC } \\
\text { TNM stage }\end{array}$ & \\
\end{tabular}} \\
\hline II & 13 & $7(53.8)$ & $6(46.2)$ & \multirow{2}{*}{0.757} \\
\hline III & 45 & $21(46.7)$ & $24(53.3)$ & \\
\hline \multicolumn{5}{|l|}{ Radiotherapy (Gy) } \\
\hline 46 & 52 & $27(51.9)$ & $25(48.1)$ & \multirow{2}{*}{0.195} \\
\hline 50 & 6 & $1(16.7)$ & $5(83.3)$ & \\
\hline \multicolumn{5}{|l|}{$\begin{array}{l}\text { Postoperative } \\
\text { UICC TNM stage }\end{array}$} \\
\hline \multicolumn{5}{|l|}{ ypT } \\
\hline урТ0-2 & 26 & $21(80.8)$ & $5(19.2)$ & \multirow[t]{2}{*}{$<0.001$} \\
\hline урТ3-4 & 32 & $7(21.9)$ & $25(78.1)$ & \\
\hline \multicolumn{5}{|l|}{ ypN } \\
\hline ypN0 & 38 & $20(52.6)$ & $18(47.4)$ & \multirow{2}{*}{0.416} \\
\hline $\mathrm{ypN+}$ & 20 & $8(40.0)$ & $12(60.0)$ & \\
\hline
\end{tabular}

Abbreviations: $\mathrm{RT}=$ radiotherapy; $\mathrm{UICC}=$ International Union Against Cancer; $\mathrm{Gx}=$ tumor differentiation is not clear.

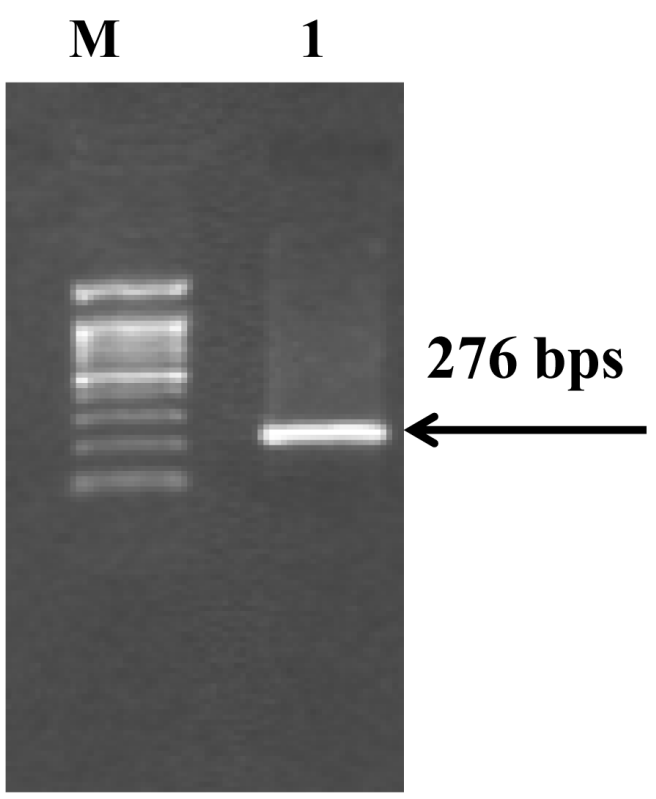

Figure 1: Amplified gene fragment of interest by PCR M=100bp DNA Marker; Lane $1=$ PCR products containing polymorphic site of rs 1800925 . 
Table 2: Analysis of genotypes associated with responsiveness to chemoradiotherapy in 58 patients

\begin{tabular}{|l|l|l|l|}
\hline \multirow{2}{*}{ Genotype } & \multicolumn{2}{|c|}{ Response to neoCRT (n, \%) } & \multirow{2}{*}{ value } \\
\cline { 2 - 4 } & good responders & poor responders & \\
\hline $\mathrm{C} / \mathrm{C}$ & $17(73.9)$ & $17(73.9)$ & \multirow{2}{*}{1.0} \\
\hline $\mathrm{T} / \mathrm{T}+\mathrm{C} / \mathrm{T}$ & $6(26.1)$ & $6(26.1)$ & \\
\hline Sequencing failure & 5 & 7 & \\
\hline
\end{tabular}

Abbreviation: neoCRT $=$ neoadjuvant chemoradiotherapy

Table 3: Analysis of genotypes associated with pCR in 58 patients

\begin{tabular}{|l|l|l|l|}
\hline \multirow{2}{*}{ Genotype } & \multicolumn{2}{|l|}{ Response to neoCRT (n,\%) } & \multirow{2}{*}{ P value } \\
\cline { 2 - 3 } & pCR & non-pCR & \\
\hline $\mathrm{C} / \mathrm{C}$ & $8(72.7)$ & $26(74.3)$ & \multirow{2}{*}{1.0} \\
\hline $\mathrm{T} / \mathrm{T}+\mathrm{C} / \mathrm{T}$ & $3(27.3)$ & $9(25.7)$ & \\
\hline Sequencing failure & 4 & 8 & \\
\hline
\end{tabular}

Table 4: Correlation between rs1800925 genotypes and ypT/ypN staging in 46 patients

\begin{tabular}{|l|l|l|l|l|}
\hline \multirow{2}{*}{ Genotype } & \multicolumn{4}{|c|}{ ypT/ ypN staging (n, \%) } \\
\cline { 2 - 5 } & \multicolumn{3}{|c|}{ ypT } & \multicolumn{2}{c|}{ ypN } \\
\cline { 2 - 5 } & ypT0-2 & ypT3-4 & ypN0 & ypN+ \\
\hline $\mathrm{C} / \mathrm{C}$ & $13(38.2)$ & $21(61.8)$ & $23(67.6)$ & $11(29.4)$ \\
\hline $\mathrm{T} / \mathrm{T}+\mathrm{C} / \mathrm{T}$ & $5(41.7)$ & $7(58.3)$ & $6(50.0)$ & $6(50.0)$ \\
\hline$P$ value & 1.0 & 0.314 \\
\hline
\end{tabular}

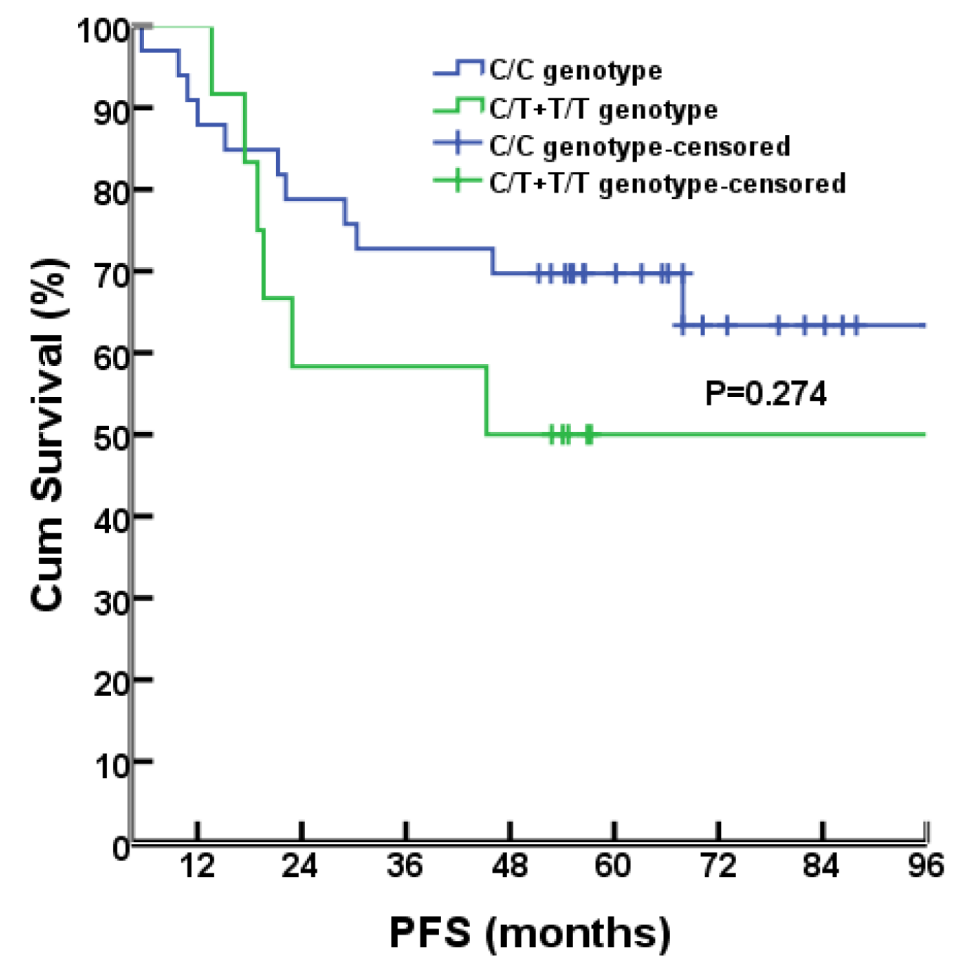

Figure 2: PFS comparison between different genotypes 


\section{Correlation between clinical characteristics and response to neoCRT}

No difference was found between the pathologic response and classical clinicopathologic parameters such as age, gender, tumor grade, pre-therapeutic TNM stage, preoperative radiation dose, and ypN staging $(P>0.05)$. Only ypT staging was associated with the pathologic response to neoCRT. Patients with good response to neoCRT usually had lower ypT staging, as showed in Table 1.

\section{Association between rs1800925 genotypes and survival}

As of July 8, 2015, the median follow-up time was 56.8 months (range, 4.4-111.6 months). Survival analyses were performed for the 46 cases that had been successfully sequenced for rs1800925. Seventeen of them had progressed diseases, 1 with liver metastases, 8 with lung metastases, 1 with concurrent liver and lung metastases, 2 with pelvic relapse, 1 with outside regional lymph nodes metastases, 1 with concurrent pelvic relapse and outside regional lymph nodes metastases, 2 with multiple bone metastases, and 1 with brain metastases. There were 12 deaths (11 dying of cancer itself, 1 dying of primary liver cancer). There were no differences between $\mathrm{C} / \mathrm{C}$ and $\mathrm{T} /$ $\mathrm{T}+\mathrm{C} / \mathrm{T}$ genotype groups for the 6-year rate of PFS $(67.6 \%$ vs. $50 \%, P=0.274$; Figure 2$)$ or OS $(76.5 \%$ vs. $66.7 \%, P=$
0.441; Figure 3).

\section{DISCUSSION}

Many studies have been focused on identifying predictive biomarkers of tumor response to neoCRT in patients with LARC [7,11,17-21,30]. Yet some results are conflicting, even from studies focusing on the same biomarker. This may be partly attributed to different study methods and materials $[31,32]$. Here, we successfully examined ILI3 rs 1800925 polymorphisms in 46 patients treated with neoCRT, and studied the association between rs 1800925 genotype and response to neoCRT, ypT/ypN staging, and prognosis. Our results were different from those reported by Ho-Pun-Cheung A et al [7].

IL13 rs1800925 C/C genotypes from good responders and poor responders in our study equally accounted for $73.9 \%(17 / 23)$. However, in the results reported by Ho-Pun- Cheung A et al [7], IL13 rs1800925 $\mathrm{C} / \mathrm{C}$ genotype accounted for only $46.2 \%$ in the poor responders and $84.4 \%$ in the good responders. This difference may be attributed to the following factors: 1) Differences in ethnicity. In this study, all patients were Han Chinese from South China, while they were Caucasian in the previously published study. Some studies showed that Han Chinese from South China and North China had conflicting results for the same SNP genotype detection $[33,34]$. 2) Differences of SNP genotyping methods. We used the gold-standard method of direct sequencing using an automatic sequencer, while in the study of Ho-Pun-

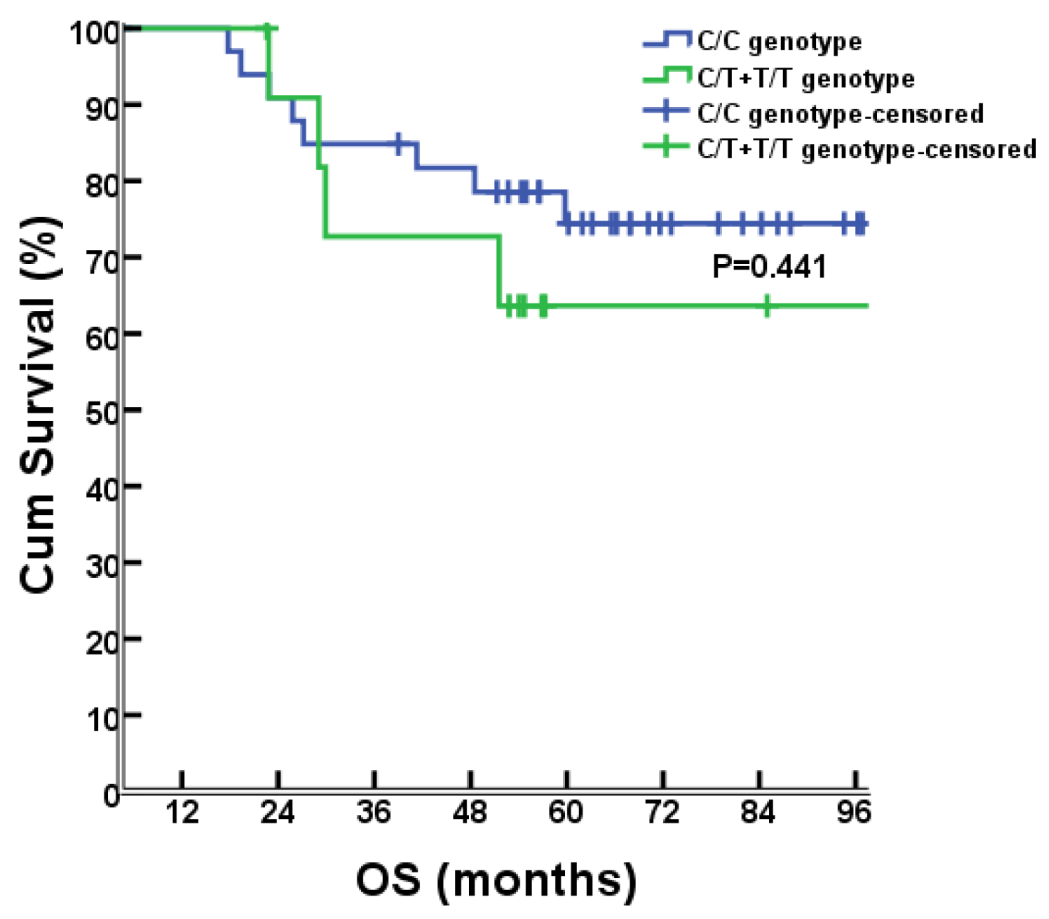

Figure 3: OS comparison between different genotypes 
Cheung A et al, the SNPlex Genotyping System (Applied Biosystems, Courtaboeuf, France) or the TaqMan allelic discrimination assay (Applied Biosystems) was used [7]. 3) Differences in genomic DNA extraction. In our study, the DNA was extracted from pre-therapeutic endoscopic biopsies of the primary rectum lesion, while it was from peripheral lymphocytes in the Ho-Pun-Cheung A et al's study [7].

The frequency of the $\mathrm{T}$ genotype in our study was $26.1 \%$, which was lower than that reported by Ho-PunCheung A et al [7] (36.6\%). Some studies showed that the IL13 rs1800925 C/C genotype was common, and that the T/T genotype was often seen in patients with asthma and allergic dermatitics [35, 36]. IL13 rs1800925 $\mathrm{T}$ allele could increase IL-13 cytokine secretion, further stimulating the body's inflammatory response and immune suppression [23, 24, 37]. Ho-Pun-Cheung A et al [7] inferred that the rs $1800925 \mathrm{~T}$ allele could inhibit chemoradiation-induced tumor immune surveillance and thereby decrease the chemoradiation effects by inducing higher IL13 transcription. However, this theory could not be supported by the results of our study.

Our study showed that different IL13 rs1800925 genotypes $(\mathrm{C} / \mathrm{C}$ vs. T/T+T/C) had no correlation with responsiveness to neoCRT, ypT/ypN staging or 6-year rate of PFS and OS for Han Chinese patients with LARC. Many clinicopathologic parameters such as age, sex, and tumor grade also had no significant association with postoperative pathologic response evaluation, and only ypT staging was associated with the pathologic response to neoCRT. These results are similar to those reported by Ho-Pun-Cheung A et al [7]. The degree of collinearity between ypT staging and responsiveness to neoCRT for patients with LARC may help to further understand their association.

A few limitations of this study need to be addressed. First, because it was a single-center retrospective study, selective bias cannot be completely avoided. However, we prospectively collected and systematically analyzed pre-therapeutic endoscopic biopsies of primary rectum lesions, so the bias may be limited. Second, the number of cases was too limited to help us to calculate a definitive minor allelic frequency of rs1800925 in the Chinese. Third, genomic DNA samples for genotyping in our study was from paraffin-embedded endoscopic biopsies of primary rectum lesions, rather than from peripheral lymphocytes. This meant that any somatic mutation or loss of heterozygoisty $(\mathrm{LOH})$ in tumor cells themselves might potentially skew our final association analysis.

In conclusion, our study could not show a significant correlation between IL13 1112 C/T (rs 1800925) and responsiveness to neoCRT and prognosis of Chinese Han patients with LARC. Further studies may be focused on the combination of clinical parameters and prospectively screening genome-wide SNPs that are associated with the carcinogenesis and tumor progression.

\section{MATERIALS AND METHODS}

\section{Ethics statement}

This investigation was conducted in accordance with the ethical standards and according to the Declaration of Helsinki and according to national and international guidelines and was approved by the Sun Yat-sen University Cancer Center's Ethics Committee.

\section{Patients}

Between January 2007 and September 2012, 58 Han Chinese patients with LARC who had histologically confirmed rectal adenocarcinoma and pre-treatment biopsy specimens in paraffin were retrospectively collected. There were 41 men and 17 women, with a median age of 58.5 years (range, $15-75$ years) at the time of diagnosis. All patients underwent neoCRT. The 7th edition of the TNM staging standard of the American Joint Committee on Cancer (AJCC) was utilized to guide pre-treatment clinical staging and postoperative pathological staging [28]. All patients signed an informed consent form prior to treatment.

The pre-treatment clinical auxiliary examinations included blood counts, liver and renal function tests, CEA, endorectal ultrasonography (EURS), pelvic magnetic resonance imaging (MRI) and/or computed tomography (CT) scans, chest CT and/or X-ray; abdominal CT and/ or MRI and/or ultrasound. A detailed description of the patients' clinicopathological characteristics and their response to chemoradiotherapy is presented in Table 1.

\section{Radiotherapy and concurrent chemotherapy}

All patients were treated with megavoltage radiotherapy $(6 \sim 8 \mathrm{MV})$ to the primary tumor and mesorectal, presacral, and internal iliac lymph nodes up to the level of the bottom of the fifth lumbar vertebra by a linear accelerator. Forty-two were treated using 3-dimensional conformal radiation therapy (3D-CRT) with one poster and two lateral fields, and received 46 Gy with a daily fraction of $2.0 \mathrm{~Gy}$ given 5 days per week. Six were treated using volumetric modulated arc therapy (VMAT), and received a concurrent boost to the tumor of 4 Gy with whole pelvic radiotherapy to a dose of $46 \mathrm{~Gy}$. Ten were treated using 2-dimensional conventional radiotherapy with 3 fields of one poster and two lateral fields, and also received a total dose of 46 Gy with a daily fraction of 2.0 Gy given 5 days per week. All patients except 1 received concurrent chemotherapy during radiotherapy, 49 of them received 2 cycles of Xelox (capecitabine $1000 \mathrm{mg} / \mathrm{m}^{2}$ given twice daily on days1-14 plus a 2-hour intravenous 
infusion of oxaliplatin $100 \mathrm{mg} / \mathrm{m}^{2}$ on $\mathrm{d} 1$, every 3 weeks), 1 received 1 cycle of Xelox, 6 received 2 cycles of mFOLFOX6 (leucovorin plus oxaliplatin plus 5-FU).

\section{Surgery and surgical specimen evaluation}

Surgery was performed at a median interval of 47 days after chemoradiotherapy (range, 29-76 days), observing principles of TME. The final choice of surgical procedure was at the discretion of the treating surgeon. The extent of the residual tumor in the resected specimen was evaluated according to the seventh International Union Against Cancer TNM staging system [28]. All patients were $\mathrm{R} 0$ resection, which was defined as histologically tumor-free.

\section{Response evaluation}

Tumor response to neoCRT was evaluated by histopathological examination of the surgically resected specimen according to the tumor regression grade (TRG) system proposed by Dworak et al [29]. The resected specimen with primary caricinoma was embedded in paraffin and its corresponding TRG evaluation was semiquantitatively determined by histopathologic examination of residual carcinoma cells vs. fibrosis or mucin pools. The TRG ranges from TRG 0 when no fibrosis is visible (no regression), to TRG 4 when no viable tumor cells are detected (i.e. complete regression). TRG $1=$ dominant tumor mass and obvious fibrosis or mucin; TRG $2=$ dominantly fibrotic or mucinous changes, with few tumor cells or groups; and TRG $3=$ very few tumor cells in fibrotic or mucinous tissue. Patients with TRG 0 to 2 were defined as poor responders, whereas those with TRG 3 to 4 were classified as good responders [21, 29].

\section{DNA extraction and SNP genotyping}

For each patient, pre-therapeutic endoscopic biopsies of the primary rectum lesion were collected. Six to eight pieces of 4-mm-thick section were taken from formalin-fixed, paraffin-embedded blocks, and deparaffinized; the remaining biologic materials were used for isolation of tumor DNA using a PureLink ${ }^{\mathrm{TM}}$ Genomic DNA Mini Kit (Life Technologies ${ }^{\mathrm{TM}}$ company) according to the manufacturer's recommendations. To determine the genotype at rs1800925, a fragment of 273 base pairs (bps) containing the polymorphic site of interest was amplified by 2 sequential polymerase chain reaction (PCR). The first PCR method was as follows: amplification was performed in a $25-\mu \mathrm{l}$ volume containing $2.5 \mu \mathrm{l}$ of $10 \times \mathrm{PCR}$ buffer (Invitrogen), $0.5 \mu \mathrm{l}$ of $10 \mathrm{mM} \mathrm{dNTP}$ (Invitrogen), $0.8 \mu \mathrm{l}$ of $50 \mathrm{mM} \mathrm{MgCl}_{2}$ (Invitrogen), $1 \mu \mathrm{l}$ each of $5 \mu \mathrm{M}$ primer (forward: 5'-AGAGAGGGGGCCTGGG-3') and (reverse:
5'-GTGATCCCCTTTGCTCACCA -3'), $1 \mu$ l of biopsyextracted DNA template, $0.2 \mu$ l of Platinum ${ }^{\circledR}$ Taq DNA polymerase (Invitrogen), and $18 \mu \mathrm{l}$ of $\mathrm{ddH} 2 \mathrm{O}$. The reaction was initiated by a pre-denaturation step at $94^{\circ} \mathrm{C}$ for $5 \mathrm{~min}$, and then denaturation at $94^{\circ} \mathrm{C}$ for $30 \mathrm{sec}$, followed by 30 cycles at $94^{\circ} \mathrm{C}$ for $30 \mathrm{sec}, 57^{\circ} \mathrm{C}$ for $30 \mathrm{sec}$, and $72^{\circ} \mathrm{C}$ for 30 $\mathrm{sec}$, with a final extension at $72^{\circ} \mathrm{C}$ for $5 \mathrm{~min}$. An additional PCR method was used to further amplify the initial PCR products. This reaction was also initiated by a denaturation step at $94^{\circ} \mathrm{C}$ for $5 \mathrm{~min}$, followed by 40 cycles at $94^{\circ} \mathrm{C}$ for $30 \mathrm{sec}, 57^{\circ} \mathrm{C}$ for $30 \mathrm{sec}$, and $72^{\circ} \mathrm{C}$ for $30 \mathrm{sec}$, with a final extension at $72^{\circ} \mathrm{C}$ for $5 \mathrm{~min}$. The PCR products were visualized on a $2 \%$ agarose gel and stained with ethidium bromide (Figure 1) then digested by Shrimp Alkaline Phosphatase, purified, and directly sequenced using a DNA sequencer (ABI 3730XL, Applied Biosystems).

\section{Follow-up}

All patients were evaluated regularly including clinical history, physical examination, laboratory investigations, EURS, pelvic MRI and/or CT scans, chest X-ray or CT, abdominal CT and/or MRI and/or ultrasound. They were followed postoperatively every 3 months in the first 2 years and then semiannually until death.

\section{Statistical analysis}

Statistical analyses were performed using SPSS 16.0 statistical software (SPSS, Inc., Chicago, IL). Betweengroup proportional differences were compared using Fisher's exact test. Disease progression was defined as patients with pelvic primary lesion and/or regional lymph nodes relapse, and/or distant metastasis detected on imaging. Progression free survival (PFS) was defined as the time between the first of radiotherapy and the appearance of cancer progression. Overall survival (OS) was considered the interval between the first radiotherapy and last follow-up or death from any cause. Comparisons between the groups with regard to PFS and OS were performed using a log-rank test and Kaplan-Meier curves. A two-sided $P$ value of $\leq 0.05$ was considered statistically significant.

\section{ACKNOWLEDGEMENTS}

We thank all other staff from the Department of Pathology, Sun Yat-sen University Cancer Center for their hard work.

\section{CONFLICTS OF INTEREST}

None. 


\section{GRANT SUPPORT}

This work was supported by Grant 81071891 of the National Natural Science Fund, China.

\section{REFERENCES}

1. Chen W, Zheng R, Zhang S, Zhao P, Zeng H, Zou X. Report of cancer incidence and mortality in China, 2010. Ann Transl Med. 2014 ; 2(7): 61-84.

2. Martin ST, Heneghan HM, Winter DC. Systematic review and meta-analysis of outcomes following pathological complete response to neoadjuvant chemoradio -therapy for rectal cancer. Br J Surg. 2012; 99(7): 918-928.

3. Sauer R, Becker H, Hohenberger W, Rödel C, Wittekind C, Fietkau R, Martus P, Tschmelitsch J, Hager E, Hess CF, Karstens JH, Liersch T, Schmidberger H, et al. Preoperative versus postoperative chemoradiotherapy for rectal cancer. N Engl J Med. 2004; 351 (17): 1731-1740.

4. Pietrzak L, Bujko K, Nowacki MP, Kepka L, Oledzki J, Rutkowski A, Szmeja J, Kladny J, Dymecki D, Wieczorek A, Pawlak M, Lesniak T, Kowalska T, et al. Quality of life, anorectal and sexual functions after preoperative radiotherapy for rectal cancer: report of a randomised trial. Radiother Oncol. 2007 ; 84(3): 217-225.

5. Maas M, Nelemans PJ, Valentini V, Das P, Rödel C, Kuo LJ, Calvo FA, García-Aguilar J, Glynne-Jones R, Haustermans K, Mohiuddin M, Pucciarelli S, Small W Jr, et al. Long-term outcome in patients with a pathological complete response after chemoradiation for rectal cancer: a pooled analysis of individual patient data. Lancet Oncol. 2010 ; 11(9): 835-844.

6. Capirci C, Valentini V, Cionini L, De Paoli A, Rodel C, Glynne-Jones R, Coco C, Romano M, Mantello G, Palazzi S, Mattia FO, Friso ML, Genovesi D, et al. Prognostic value of pathologic complete response after neoadjuvant therapy in locally advanced rectal cancer: long-term analysis of 566 ypCR patients. Int J Radiat Oncol Biol Phys. 2008; 72(1):99-107.

7. Ho-Pun-Cheung A, Assenat E, Bascoul-Mollevi C, Bibeau $\mathrm{F}$, Boissière-Michot $\mathrm{F}$, Thezenas S, Cellier D, Azria D, Rouanet P, Senesse P, Ychou M, Lopez-Crapez E. A largescale candidate gene approach identifies SNPs in SOD2 and IL13 as predictive markers of response to preoperative chemoradiation in rectal cancer. Pharmacogenomics J. 2011; 11(6): 437- 443.

8. Maas M, Beets-Tan RG, Lambregts DM, Lammering G, Nelemans PJ, Engelen SM, van Dam RM, Jansen RL, Sosef M, Leijtens JW, Hulsewé KW, Buijsen J, Beets GL. Wait-and-see policy for clinical complete responders after chemoradiation for rectal cancer. J Clin Oncol. 2011; 29 (35): 4633-4640.

9. O’Neill BD, Brown G, Heald RJ, Cunningham D, Tait DM. Non-operative treatment after neoadjuvant chemoradiotherapy for rectal cancer. Lancet Oncol. 2007; 8 (7): 625-633.

10. Habr-Gama A, Perez RO, Nadalin W, Sabbaga J, Ribeiro U Jr, Silva e Sousa AH Jr, Campos FG, Kiss DR, GamaRodrigues J. Operative versus non-operative treatment for stage 0 distal rectal cancer following chemoradiation therapy: long-term results. Ann Surg. 2004 ; 240(4):711718.

11. Garcia-Aguilar J, Chen Z, Smith DD, Li W, Madoff RD, Cataldo P, Marcet J, Pastor C. Identification of a biomarker profile associated with resistance to neoadjuvant chemoradiation therapy in rectal cancer. Ann Surg. 2011; 254(3): 486- 492.

12. Sanghera P, Wong DW, McConkey CC, Geh JI, Hartley A. Chemoradiotherapy for rectal cancer: an updated analysis of factors affecting pathological response. Clin Oncol. 2008; 20(2): 176-183.

13. Yoon SM, Kim DY, Kim TH, Jung KH, Chang HJ, Koom WS, Lim SB, Choi HS, Jeong SY, Park JG. Clinical parameters predicting pathologic tumor response after preoperative chemoradiotherapy for rectal cancer. Int $\mathrm{J}$ Radiat Oncol Biol Phys. 2007; 69(4):1167-1172.

14. Garcia-Aguilar J, Smith DD, Avila K, Bergsland EK, Chu P, Krieg RM; Timing of Rectal Cancer Response to Chemoradiation Consortium. Optimal timing of surgery after chemoradiation for advanced rectal cancer: preliminary results of a multicenter, nonrandomized phase II prospective trial. Ann Surg. 2011; 254(1): 97-102.

15. Kalady MF, de Campos-Lobato LF, Stocchi L, Geisler DP, Dietz D, Lavery IC, Fazio VW. Predictive factors of pathologic complete response after neoadjuvant chemoradiation for rectal cancer. Ann Surg. 2009; 250(4): 582-589.

16. Caudle AS, Kim HJ, Tepper JE, O’Neil BH, Lange LA, Goldberg RM, Bernard SA, Calvo BF, Meyers MO. Diabetes mellitus affects response to neoadjuvant chemoradiotherapy in the management of rectal cancer. Ann Surg Oncol. 2008; 15(7):1931-1936.

17. Yan $\mathrm{H}, \mathrm{Yu}$ J, Wang R, Jiang $\mathrm{S}$, Zhu K, Mu D, Xu Z. Prognostic value of Smac expression in rectal cancer patients treated with neoadjuvant therapy. Med Oncol. 2012; 29(1): 168-173.

18. Fucini C, Messerini L, Saieva C, Orzalesi L, Carroni V, Bartolini N. Apoptotic proteins as prognostic markers and indicators of radiochemosensitivity in stage II/III rectal cancers. Colorectal Dis. 2012; 14(2):e64-71.

19. Choi $\mathrm{S}, \mathrm{Ku}$ JL. Resistance of colorectal cancer cells to radiation and 5-FU is associated with MELK expression. Biochem Biophys Res Commun. 2011; 412(2): 207-213.

20. Spindler KL, Nielsen JN, Lindebjerg J, Brandslund I, Jakobsen A. Prediction of response to chemoradiation in rectal cancer by a gene polymorphism in the epidermal growth factor receptor promoter region. Int J Radiat Oncol Biol Phys. 2006; 66(2): 500-504. 
21. Ho-Pun-Cheung A, Assenat E, Thezenas S, Bibeau F, Rouanet P, Azria D, Cellier D, Grenier J, Ychou M, Senesse P, Lopez-Crapez E. Cyclin D1 gene G870A polymorphism predicts response to neoadjuvant radiotherapy and prognosis in rectal cancer. Int J Radiat Oncol Biol Phys. 2007; 68(4): 1094-1101.

22. Zhou R, Qian S, Gu X, Chen Z, Xiang J. Interleukin-13 and its receptors in colorectal cancer. Biomed Rep. 2013; 1(5): 687-690

23. Terabe M, Park JM, Berzofsky JA. Role of IL-13 in regulation of anti-tumor immunity and tumor growth. Cancer Immunol Immunother. 2004; 53(2):79-85.

24. Park JM, Terabe M, Donaldson DD, Forni G, Berzofsky JA. Natural immuno- surveillance against spontaneous, autochthonous breast cancers revealed and enhanced by blockade of IL-13-mediated negative regulation. Cancer Immunol Immunother. 2008; 57(6): 907- 912.

25. Sadeghnejad A, Karmaus W, Hasan Arshad S, Ewart S. IL13 gene polymerphism association with cord serum immunoglobulin E. Pediatr Allergy Immunol. 2007; 18 (4):288-292.

26. Walczak A, Przybyłowska K, Trzciński R, Sygut A, Dziki L, Dziki A, Majsterek I. Association of $-1112 \mathrm{c} / \mathrm{t}$ promoter region polymorphism of the interleukin 13 gene with occurrence of colorectal cancer. Pol Przegl Chir. 2011; 83(1):27-231.

27. Walczak A, Przybylowska K, Dziki L, Sygut A, Chojnacki C, Chojnacki J, Dziki A, Majsterek I. The 1L-8 and IL-13 gene polymorphisms in inflammatory bowel disease and colorectal cancer. DNA Cell Biol. 2012; 31(8):1431-1438.

28. Edge SB, Byrd DR, Compton CC. American Joint Committee on Cancer (AJCC) Cancer Staging Manual. 7th ed. Edited by Edge SB, Byrd DR, Compton CC. Chicago, USA: IL: springer, Inc; 2010:143-164.

29. Dworak O, Keilholz L, Hoffmann A. Pathological features of rectal cancer after preoperative radiochemotherapy. Int J Colorectal Dis. 1997; 12(1):19-23.

30. Yeo SG, Kim DY, Kim KH, Ku JL, Kim JS, Cho MJ, Kim ES, Yoo BC. Hydroxymethylglutaryl-coenzyme a synthase 2 expression is associated with chemoradiotherapy responses in colorectal cancer. Dis Colon Rectum. 2012; 55(6): 686-694.
31. Chen MB, Wu XY, Yu R, Li C, Wang LQ, Shen W, Lu PH. $\mathrm{P} 53$ status as a predictive biomarker for patients receiving neoadjuvant radiation-based treatment: a meta-analysis in rectal cancer. PLoS One. 2012; 7(9):e45388.

32. Jakob C, Liersch T, Meyer W, Becker H, Baretton GB, Aust DE. Predictive value of Ki67 and p53 in locally advanced rectal cancer: correlation with thymidylate synthase and histopathological tumor regression after neoadjuvant 5-FUbased chemoradiotherapy. World J Gastroenterol. 2008; 14(7):1060-1066.

33. Xiong F, Wu C, Bi X, Yu D, Huang L, Xu J, Zhang T, Zhai K, Chang J, Tan W, Cai J, Lin D. Risk of genome-wide association study-identified genetic variants for colorectal cancer in a Chinese population. Cancer Epidemiol Biomarkers Prev. 2010; 19(7): 1855-1861.

34. Ho JW, Choi SC, Lee YF, Hui TC, Cherny SS, GarciaBarceló MM, Carvajal-Carmona L, Liu R, To SH, Yau TK, Chung CC, Yau CC, Hui SM, et al. Replication study of SNP associations for colorectal cancer in Hong Kong Chinese. Br J Cancer. 2011; 104(2):369-375.

35. Howard TD, Whittaker PA, Zaiman AL, Koppelman GH, Xu J, Hanley MT, Meyers DA, Postma DS, Bleecker ER. Identification and association of polymorphisms in the interleukin-13 gene with asthma and atopy in a Dutch population. Am J Respir Cell Mol Biol. 2001; 25(3):377384.

36. Hummelshoj T, Bodtger U, Datta P, Malling HJ, Oturai A, Poulsen LK, Ryder LP, Sorensen PS, Svejgaard E, Svejgaard A. Association between an interleukin -13 promoter polymorphism and atopy. Eur J Immunogenet. 2003;30(5): 355-359.

37. Cameron L, Webster RB, Strempel JM, Kiesler P, Kabesch M, Ramachandran H, Yu L, Stern DA, Graves PE, Lohman IC, Wright AL, Halonen M, Klimecki WT, et al. Th2 cellselective enhancement of human IL13 transcription by IL13-1112 C > T, a polymorphism associated with allergic inflammation. J Immunol. 2006; 177(12): 8633-8642. 